\title{
Analysis of Laminated Composites: A Web-based Computer Program Based on Classical Lamination Theory
}

\author{
*Dr. H. Estrada, P. E. (corresponding author) and *Dr. F. Aguiniga \\ *Civil Engineering Program \\ Texas A\&M University - Kingsville \\ MSC 194 \\ Kingsville, Texas 78363 \\ Hector.Estrada@tamuk.edu
}

\begin{abstract}
This paper presents the description of a web-based computer program for the analysis of laminated composites using Classical Lamination Theory. The program was developed using an object-oriented programming methodology, Java, and runs from any web page. The program is intended for educational purposes, but it can also be used in industry. It is currently used in a mechanics of composites course taught at Texas A\&M University-Kingsville. The response from the students after using the program has been very positive and encouraging. The students primarily complement the program's interface, which is very user-friendly. Furthermore, the program is practical and can be used to compute the stresses and strains in any laminated composites. The main objective of the paper is to present the program to other potential users in academia and industry.

\section{Introduction}

In order to design a structure (after the design loads have been determined) it is necessary to conduct an analysis to find the internal forces in each structural element, which are then used to determine the strains and stresses. These stresses are then used to assess the capacity of the system. This process is straightforward for structures composed of isotropic materials; however, for structures composed of fiber reinforced plastic materials (composites), the process can be much more involved, particularly the step where the internal forces are converted to strains and stresses. A number of theories have been developed to convert internal forces to strains and stresses; the most practical of which is Classical Lamination Theory ${ }^{1,2}$ - from hereon referred to as CLT. The computer program described in this paper calculates the stresses at a point in a composite structure given the internal forces (axial and shear forces and bending moments) and the material properties. The program is based on CLT.
\end{abstract}

The CLT analysis to determine strains and stresses is complex, involving tedious calculations. Students in Engineering Mechanics of Fiber Composites at Texas A\&M University-Kingsville 
(TAMUK) had been required to perform these calculations by hand ${ }^{3}$ prior to the development of the program presented here. This required the instructor to spend a large portion of the course teaching the calculation procedures rather than helping the students understand the nature and effect of these stresses on structures. Furthermore, students were able to solve only very simple problems with no practical applicability. Also, students commented that the processes was a mathematical exercise and did not help them understand the mechanical behavior of different composite systems. Therefore, the project presented here is intended to be responsive to this complain by using computers to perform the tedious calculations, taking advantage of their speed and consistency. Since the program has been unitized in the class, the student comments have been very positive. Students are still required to solve simple problems both by hand and program, which has significantly improve their confidence with problem solving without the loss of capability of doing problems by hand. The area where the program has made the most significant difference is in the solution of more involved practical problems including design, where it may be required to analyze a laminate several times to arrive at an optimum system. This has greatly enhanced the physical intuition of the students for the behavior of composite laminates.

The computer program was developed using Java because it is one of the most popular object-oriented programming languages that allows the programs to run over the internet and it allows the programmer to use features, such as pull down menus, etc., typically found in conventional programs. This program was developed because there are no simple computer programs that isolate CLT, though there are a number of "canned" programs that perform these calculations, including sophisticated structural analysis ones such as ABAQUS ${ }^{4}$.

\section{Overview of CLT}

\section{$\underline{\text { Laminae Stiffness Matrix }}$}

The structural analysis for composite and homogeneous systems is similar, except for the constitutive model used to characterize the behavior of the system when subjected to mechanical loading. The composite system is much more complex given that it is composed of two or more distinct materials, which are usually combined in the form of plies (laminae) bonded together to form a laminate. In the mathematical model for the constitutive behavior of a composite lamina, five property constants are required (Longitudinal Modulus of Elasticity, $E_{L}$; Transverse Modulus of Elasticity, $E_{T}$; Shear Modulus of Elasticity, $G_{L T}$; Major Poison's Ratio, $v_{L T}$; and Minor Poison's Ratio, $v_{T L}$ - four of which are independent, $v_{L T} / E_{L}=v_{T L} / E_{T}-$ Agarwal et al. ${ }^{1}$ describe the computation of these quantities from the properties of each constituent). Subscripts $\mathrm{L}$ and $\mathrm{T}$ indicate the principal directions of the materials, as shown in Figure 1. These constants can be determined from the properties of the composite constituents ${ }^{1}$, and are needed for the analysis. Furthermore, it is customary to treat the laminae as transversely isotropic systems with the following constitutive relationship:

$$
\left\{\begin{array}{c}
\sigma_{L} \\
\sigma_{T} \\
\tau_{L T}
\end{array}\right\}=\left[\begin{array}{ccc}
Q_{11} & Q_{12} & 0 \\
Q_{12} & Q_{22} & 0 \\
0 & 0 & Q_{66}
\end{array}\right]\left\{\begin{array}{c}
\varepsilon_{L} \\
\varepsilon_{T} \\
\gamma_{L T}
\end{array}\right\}
$$


where,

$$
\begin{gathered}
Q_{11}=\frac{E_{L}}{1-v_{L T} v_{T L}}, \\
Q_{12}=\frac{v_{L T} E_{T}}{1-v_{L T} v_{T L}}, \\
Q_{22}=\frac{E_{T}}{1-v_{L T} v_{T L}}, \\
Q_{66}=G_{L T},
\end{gathered}
$$
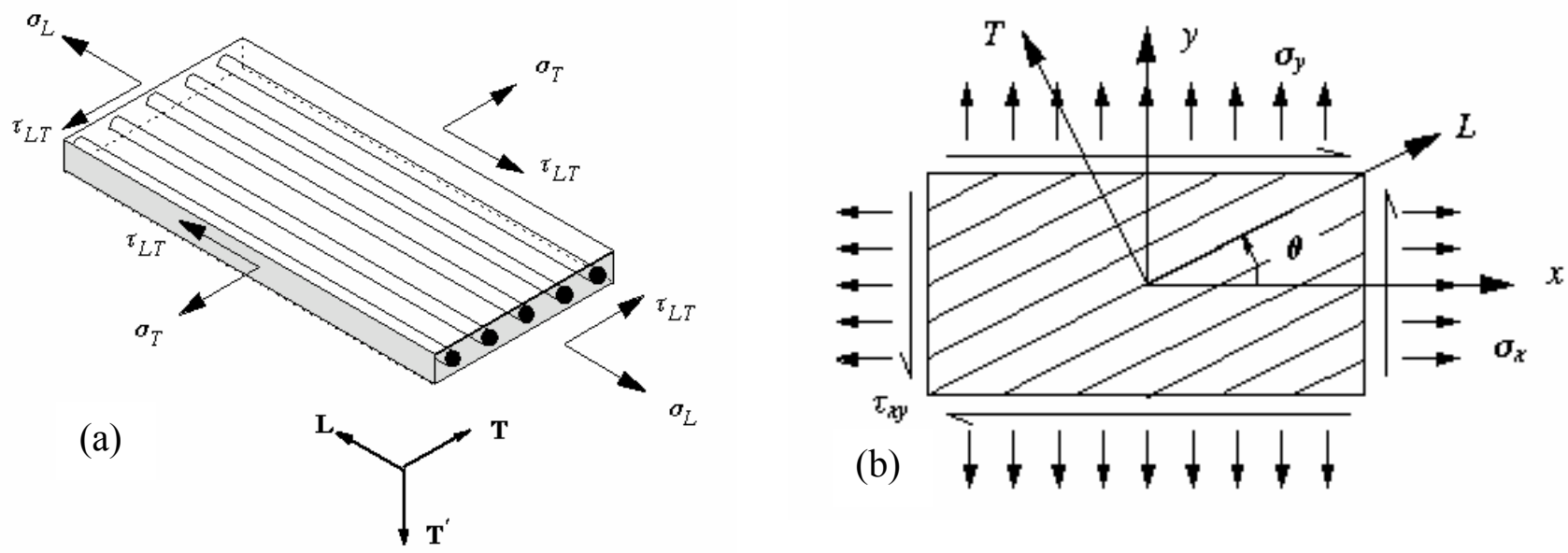

Figure 1: The State of Stress for a Lamina in the (a) Material and (b) General Directions.

The stresses can be transformed from material (laminae $L, T, \& T^{\prime}$ ) coordinates to general (laminate $x, y, \& z$ ) coordinates using tensorial transformation laws derived using Figure 1 . The resulting stress transformation is:

$$
\left\{\begin{array}{l}
\sigma_{x} \\
\sigma_{y} \\
\tau_{x y}
\end{array}\right\}=\left[\begin{array}{ccc}
C^{2} & S^{2} & -2 S C \\
S^{2} & C^{2} & 2 S C \\
S C & -S C & C^{2}-S^{2}
\end{array}\right]\left\{\begin{array}{c}
\sigma_{L} \\
\sigma_{T} \\
\tau_{L T}
\end{array}\right\}
$$

where, $C=\cos \theta$ and $S=\sin \theta$.

With this result, the constitutive relation in terms of laminate coordinates is ${ }^{2}$ :

$$
\left\{\begin{array}{c}
\sigma_{x} \\
\sigma_{y} \\
\tau_{x y}
\end{array}\right\}=\left[\begin{array}{lll}
\bar{Q}_{11} & \bar{Q}_{12} & \bar{Q}_{16} \\
\bar{Q}_{12} & \bar{Q}_{22} & \bar{Q}_{26} \\
\bar{Q}_{16} & \bar{Q}_{26} & \bar{Q}_{66}
\end{array}\right]\left\{\begin{array}{c}
\varepsilon_{x} \\
\varepsilon_{y} \\
\gamma_{x y}
\end{array}\right\}
$$

where, the matrix is know as the rotated laminae stiffness matrix and the bar quantities are transformed laminae stiffness matrix coefficients. See Jones ${ }^{2}$ describes the procedure followed to obtain the laminae stiffness matrix from the material properties. 


\section{Laminate Stiffness Matrix}

Equilibrium, kinematics (strain displacement relations), and the constitutive relations (Eq. 3) are combined to obtain the stress resultants for the composite laminate (Figure 2) at a point. The relationship between the stress resultants $\left(N_{i}\right.$ and $\left.M_{i}\right)$ and the mid-plane strains $\left(\varepsilon_{i}\right)$ and curvatures $\left(k_{i}\right)$ yields the laminate stiffness matrix, otherwise known as the ABD matrix.

$$
\begin{aligned}
& \left\{\begin{array}{l}
N_{x} \\
N_{y} \\
N_{x y}
\end{array}\right\}=\left[\begin{array}{lll}
A_{11} & A_{12} & A_{16} \\
A_{12} & A_{22} & A_{26} \\
A_{16} & A_{26} & A_{66}
\end{array}\right]\left\{\begin{array}{c}
\varepsilon_{x}^{o} \\
\varepsilon_{y}^{o} \\
\gamma_{x y}^{o}
\end{array}\right\}+\left[\begin{array}{lll}
B_{11} & B_{12} & B_{16} \\
B_{12} & B_{22} & B_{26} \\
B_{16} & B_{26} & B_{66}
\end{array}\right]\left\{\begin{array}{l}
k_{x} \\
k_{y} \\
k_{x y}
\end{array}\right\} \\
& \left\{\begin{array}{l}
M_{x} \\
M_{y} \\
M_{x y}
\end{array}\right\}=\left[\begin{array}{lll}
B_{11} & B_{12} & B_{16} \\
B_{12} & B_{22} & B_{26} \\
B_{16} & B_{26} & B_{66}
\end{array}\right]\left\{\begin{array}{c}
\varepsilon_{x}^{o} \\
\varepsilon_{y}^{o} \\
\gamma_{x y}^{o}
\end{array}\right\}+\left[\begin{array}{lll}
D_{11} & D_{12} & D_{16} \\
D_{12} & D_{22} & D_{26} \\
D_{16} & D_{26} & D_{66}
\end{array}\right]\left\{\begin{array}{l}
k_{x} \\
k_{y} \\
k_{x y}
\end{array}\right\}
\end{aligned}
$$

where,

$$
\begin{aligned}
A_{i j} & =\sum_{k=1}^{n}\left(\overline{Q_{i j}}\right)_{k}\left(h_{k}-h_{k-1}\right), \\
B_{i j} & =\frac{1}{2} \sum_{k=1}^{n}\left(\overline{Q_{i j}}\right)_{k}\left(h_{k}^{2}-h_{k-1}^{2}\right), \\
D_{i j} & =\frac{1}{3} \sum_{k=1}^{n}\left(\overline{Q_{i j}}\right)_{k}\left(h_{k}^{3}-h_{k-1}^{3}\right) .
\end{aligned}
$$

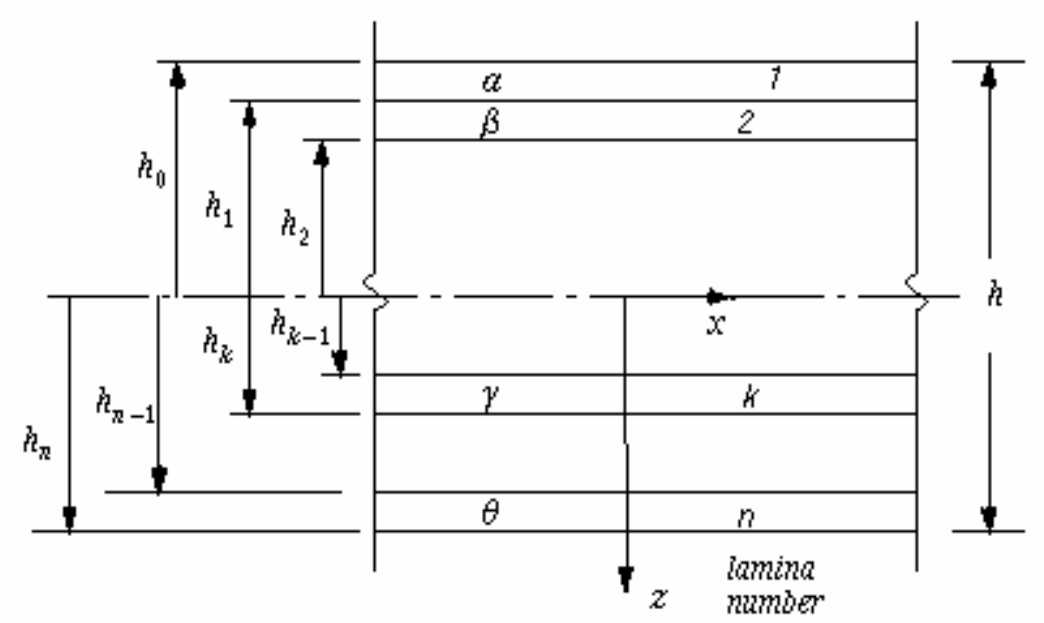

Figure 2: Geometry of Laminate.

\section{$\underline{\text { Laminae Stresses }}$}

The rotated stresses can be obtained using the stress-strain relations given by Eq. (3) and the following relationship between the general strains and the mid-plane strains and curvatures:

$$
\left\{\begin{array}{c}
\varepsilon_{x} \\
\varepsilon_{y} \\
\gamma_{x y}
\end{array}\right\}=\left\{\begin{array}{c}
\varepsilon_{x}^{o} \\
\varepsilon_{y}^{o} \\
\gamma_{x y}^{o}
\end{array}\right\}+z\left\{\begin{array}{l}
k_{x} \\
k_{y} \\
k_{x y}
\end{array}\right\}
$$




\section{First Ply-Failure}

Several failure criteria are frequently applied to check the ultimate strength of a composite structural element. In the composite analysis tool program, the Maximum Work Theory is used to check for the onset of failure of a laminate. This theory was derived by Tsai ${ }^{2}$ from a yield criterion for anisotropic materials proposed by $\mathrm{Hill}^{2}$ and often in literature referred to as the Tsai-Hill failure criterion. The relation that describes the failure condition is given as:

$$
\left(\frac{\sigma_{L}}{\sigma_{L U}}\right)^{2}-\left(\frac{\sigma_{L}}{\sigma_{L U}}\right)\left(\frac{\sigma_{T}}{\sigma_{L U}}\right)+\left(\frac{\sigma_{T}}{\sigma_{T U}}\right)^{2}+\left(\frac{\tau_{L T}}{\sigma_{L T U}}\right)^{2}<1.0
$$

where,

$$
\begin{aligned}
& \sigma_{L U} \text { is the longitudinal ultimate strength. } \\
& \sigma_{T U} \text { is the transverse ultimate strength. } \\
& \sigma_{L T U} \text { is the inplane ultimate shear strength. }
\end{aligned}
$$

When Eq. (7) is violated, the ply under consideration has failed. It should be noted here that when the stress in the lamina for the $T$ or the $L$ direction is compressive, the appropriate ultimate compressive strength value should be used in Eq. (7). The left hand side of Eq. (7) is customarily known as the Failure Index.

\section{Flowchart of Calculation Procedures}

A flowchart of the calculation steps used in the program is depicted in Figure 3.

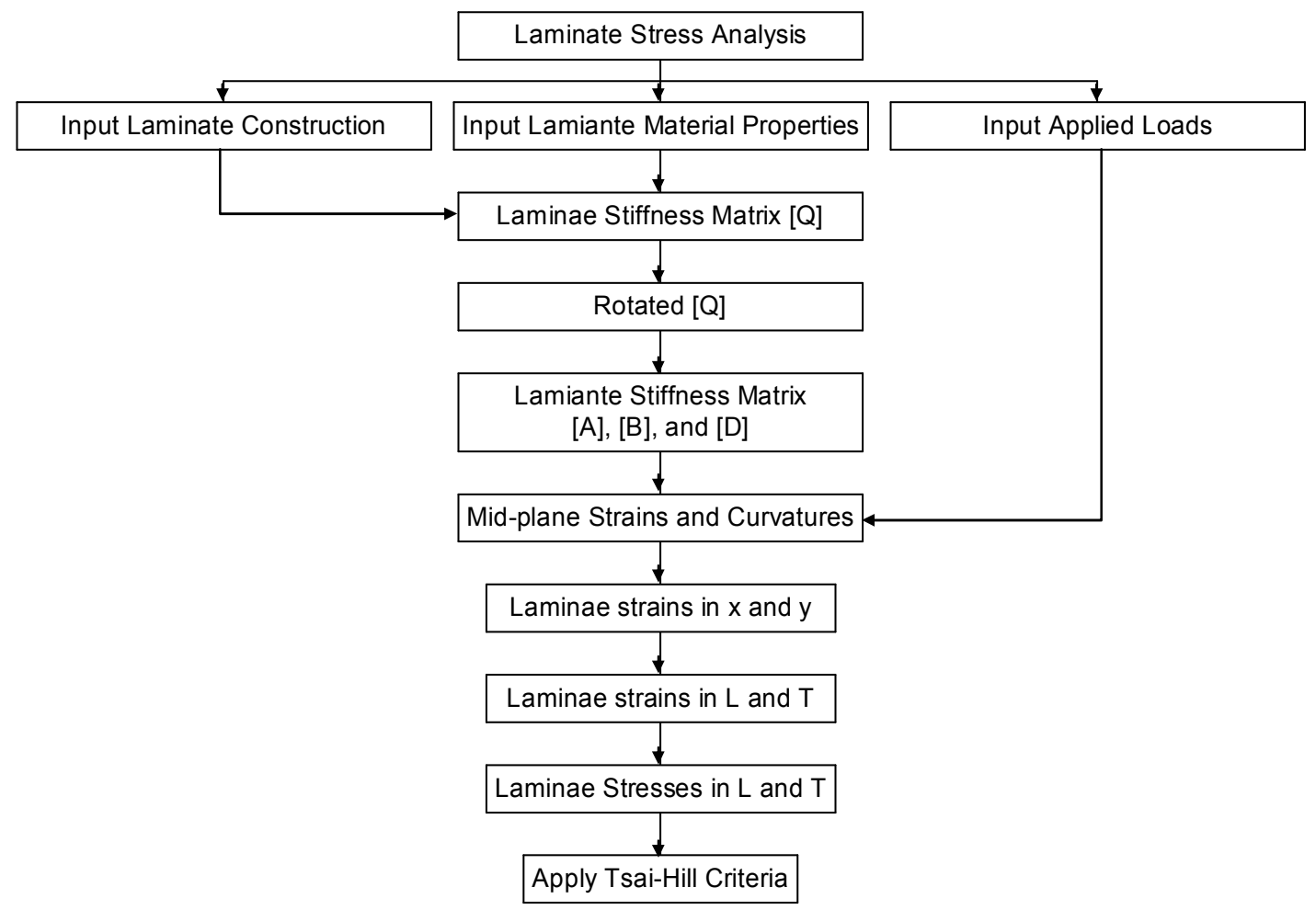

Figure 3: Flowchart of Laminate Stress Analysis. 


\section{Overview of Composite Analysis Tool Program}

This section provides a brief overview of the Composite Analysis Tool program. The topics covered include input, processing, and output. Also discussed are the related graphical user interface dialog boxes and views. The workspace window of the program is shown in Figure 4. It has three main menus: Input Data, Calculation, and Show Data. This window may be moved, minimized, or closed using standard Microsoft Windows operations. The menus on the Menu Bar follow standard Microsoft Windows operations.

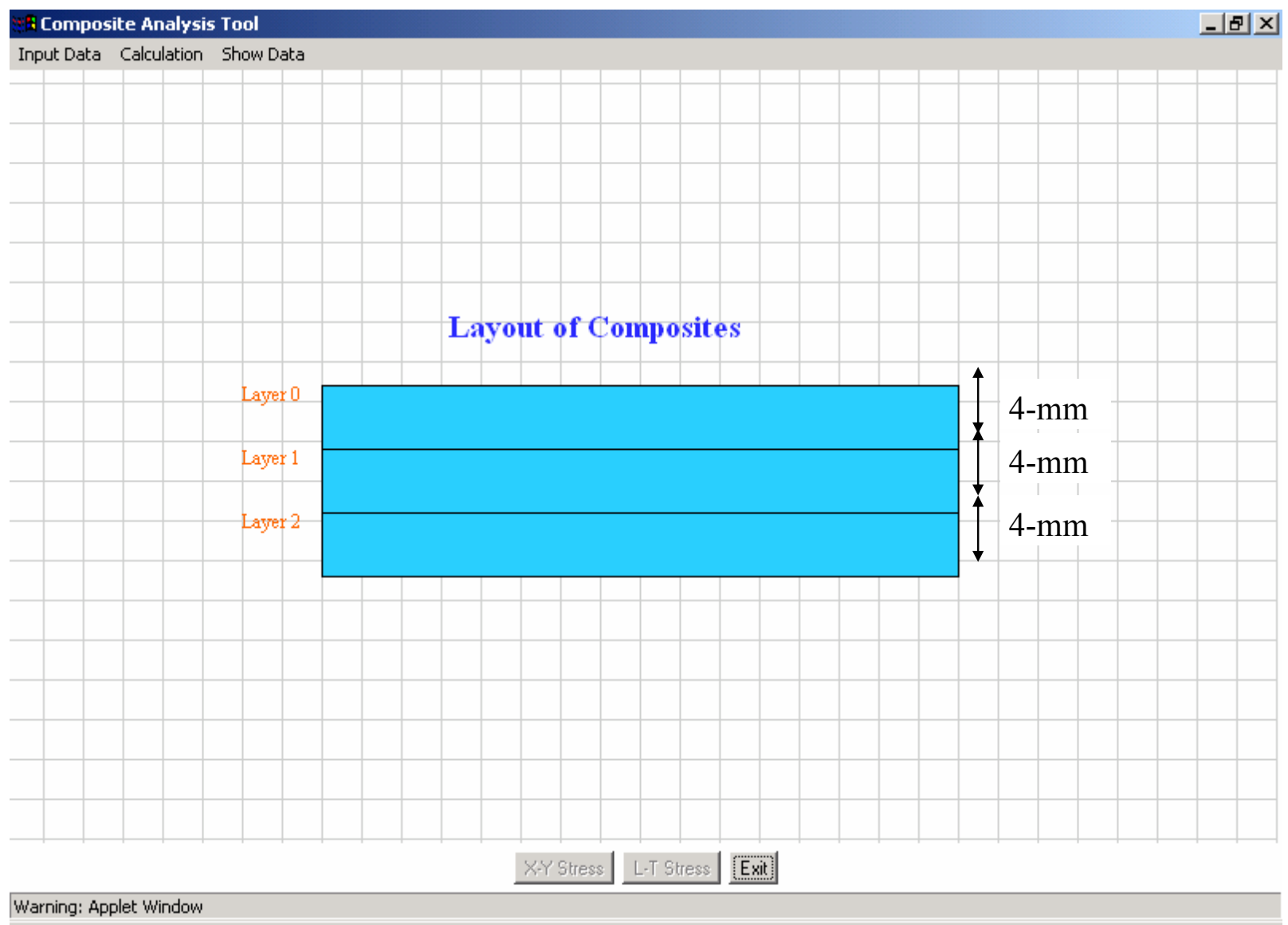

Figure 4: Composite Analysis Tool Workspace Window.

\section{$\underline{\text { Input Data }}$}

The Input Data menu contains four items: General Data, Material Properties, Load, and Layer Information. The General Data dialog window is shown in Figure 5 and it includes general information about the problem. After the required data is entered, click OK to continue to the next step. (The numbers are included here as part of the analysis verification problem discussed in the next section.) All the dimensions must be entered in SI units (Pascals and millimeters). The Material Properties dialog window is shown in Figure 6 and it includes elastic and strength material properties. After the required data is entered, click OK to continue to the next step. The Load dialog window is shown in Figure 7 and it includes the general loading at a specific point. After the required data is entered, click OK to continue to the next step. The Layer Info dialog 
window is shown in Figure 8 and it includes information about each of the layers - note that the material type number starts at zero. After the required data is entered, click $\mathrm{OK}$ and close to begin running the analysis.

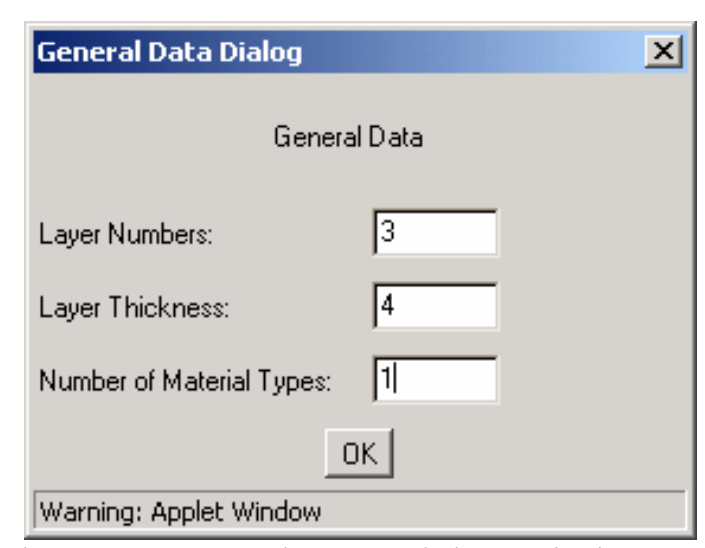

Figure 5: General Data Dialog Window.

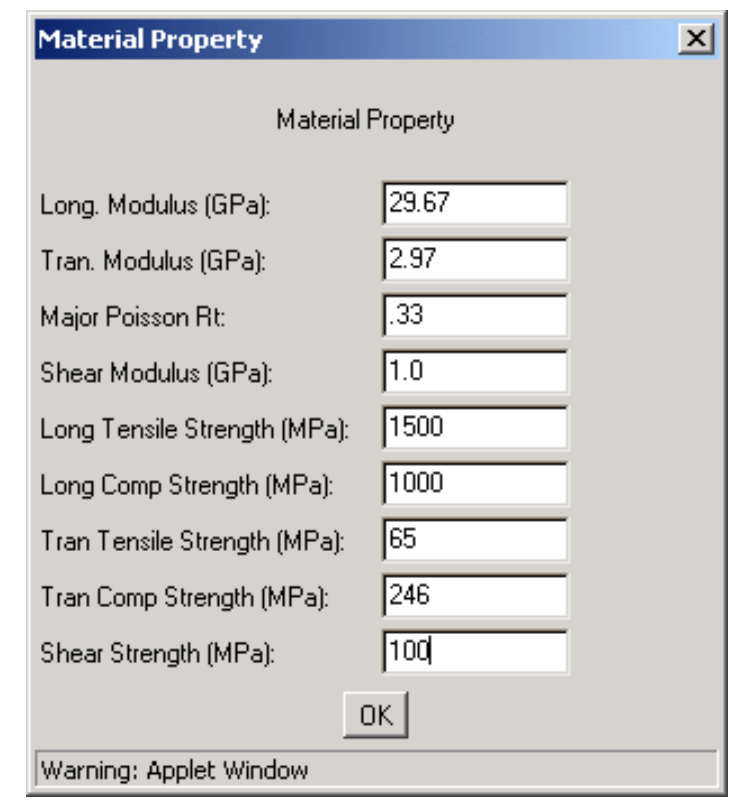

Figure 6: Material Properties Dialog Window.

To analyze the laminate for the given loading, run the program by selecting the Stress Dist menu in the Calculation pull down menu. The results can be displayed graphically in the $\mathrm{x}-\mathrm{y}$ laminate coordinate system or the L-T lamina coordinate system by clicking the corresponding button at the bottom of the dialog box. The numeric values in consistent units are also displayed in the window. To check for first ply-failure, the FFP menu is selected from the Calculation pull-down menu. 


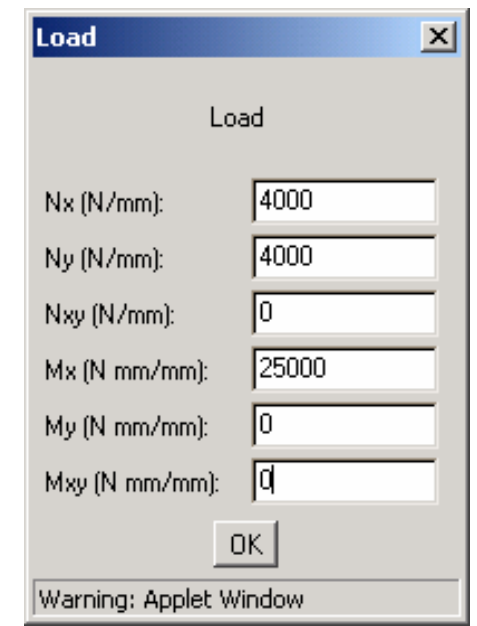

Figure 7: Loading Dialog Window.

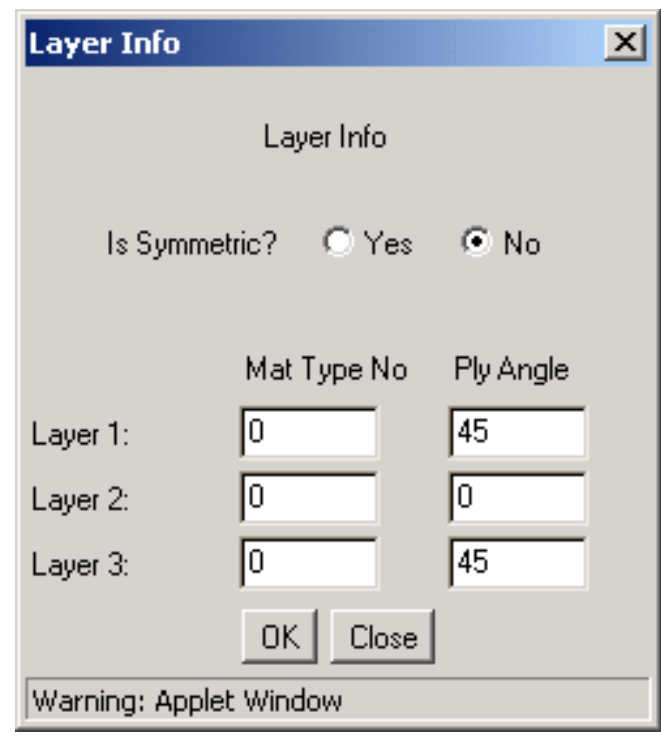

Figure 8: Layer Information Dialog Window.

\section{Verification of the Computer Program Calculations}

In this section, a specific example from Engineering Mechanics of Fiber Composites class notes $^{3}$ is solved to verify the accuracy of the calculations performed by the Composites Analysis Tool program. The lay-up is shown in Figure 4, with ply thickness of 4- $m m$ and lay-up construction of $\left[+45^{\circ} / 0^{\circ} / 45^{\circ}\right]$, which is entered in the Layer Info dialog window, Figure 8 . The material and strength properties are given in Figure 6 . The units for each quantity are listed in parenthesis to the right of the quantity name. The loading is given in Figure 7, with the appropriate units listed to the right of the load quantity name.

Hand calculations were used to check the solution by the Composites Analysis Tool program. Figures 9 and 10 present the calculations using the Composites Analysis Tool program. The values for the stresses obtained using the Composites Analysis Tool program are very close to 
those obtained by the hand calculation approach ${ }^{3}$.

\section{Conclusions}

A program for the analysis of laminated composites was developed. This program is based on CLT. The program was written in Java using object-oriented programming methodology. The program is intended to simplify the tedious calculations involved in determining stresses in a laminated composite.

The program is a web based application and has functionality similar to Microsoft Windows programs. It only allows the user to manually input data; the capability of loading data from a file is being developed. Output data can be printed, but not stored on standard computer storage media, which is a severe limitation. However, a future version of the program will include the capability of saving results to a file. The Composites Analysis Tool program is an efficient tool for determining stresses in composite laminates. Furthermore, although the program produces accurate results for the example problem given in this paper, it is recommended that the program be tested before being used in practical engineering calculations.

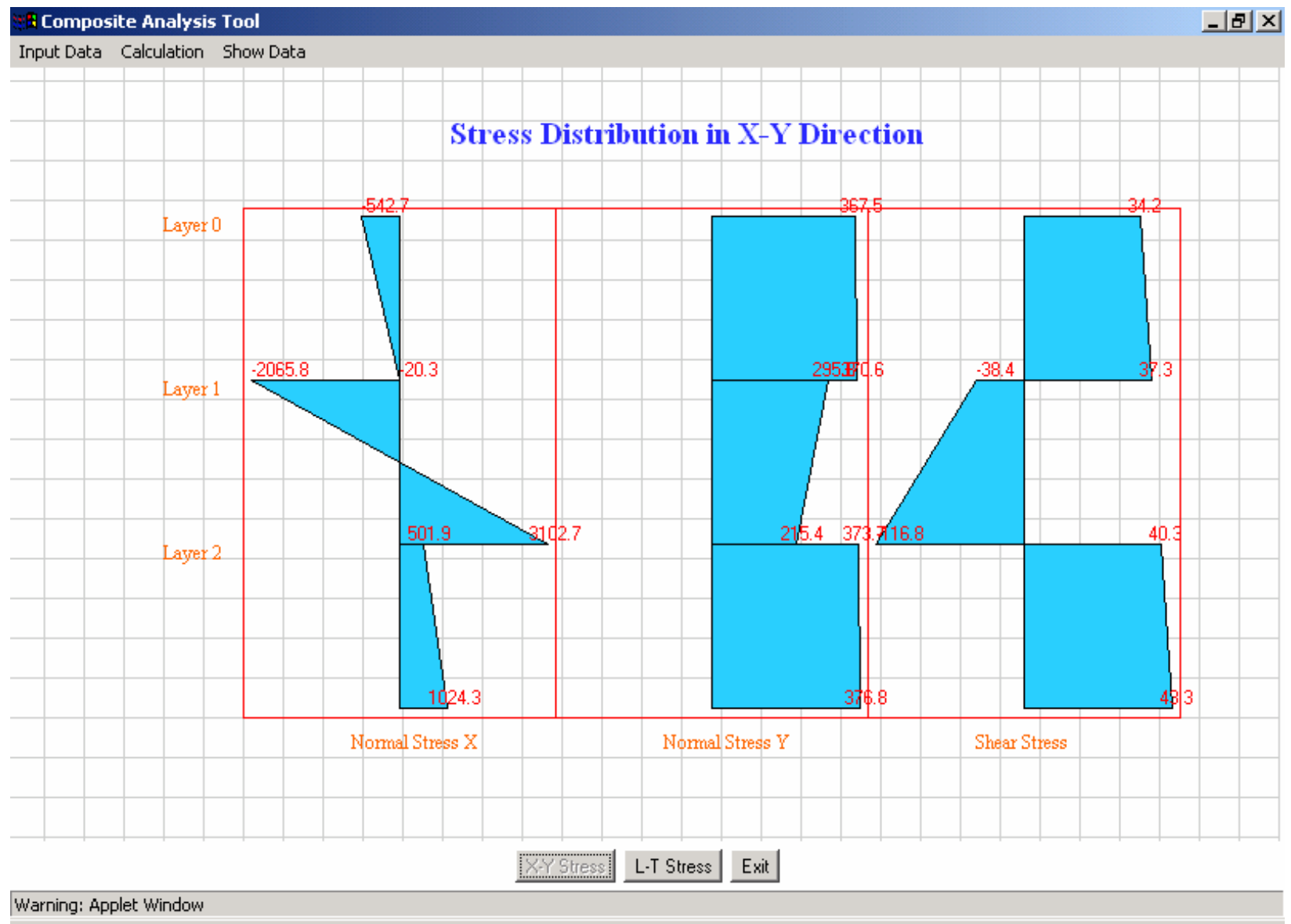

Figure 9: Results of Calculations from Program for Stresses in Laminate (x-y) coordinates.

Proceedings of the 2005 American Society for Engineering Education Annual Conference \& Exposition Copyright (C) 2005, American Society for Engineering Education 


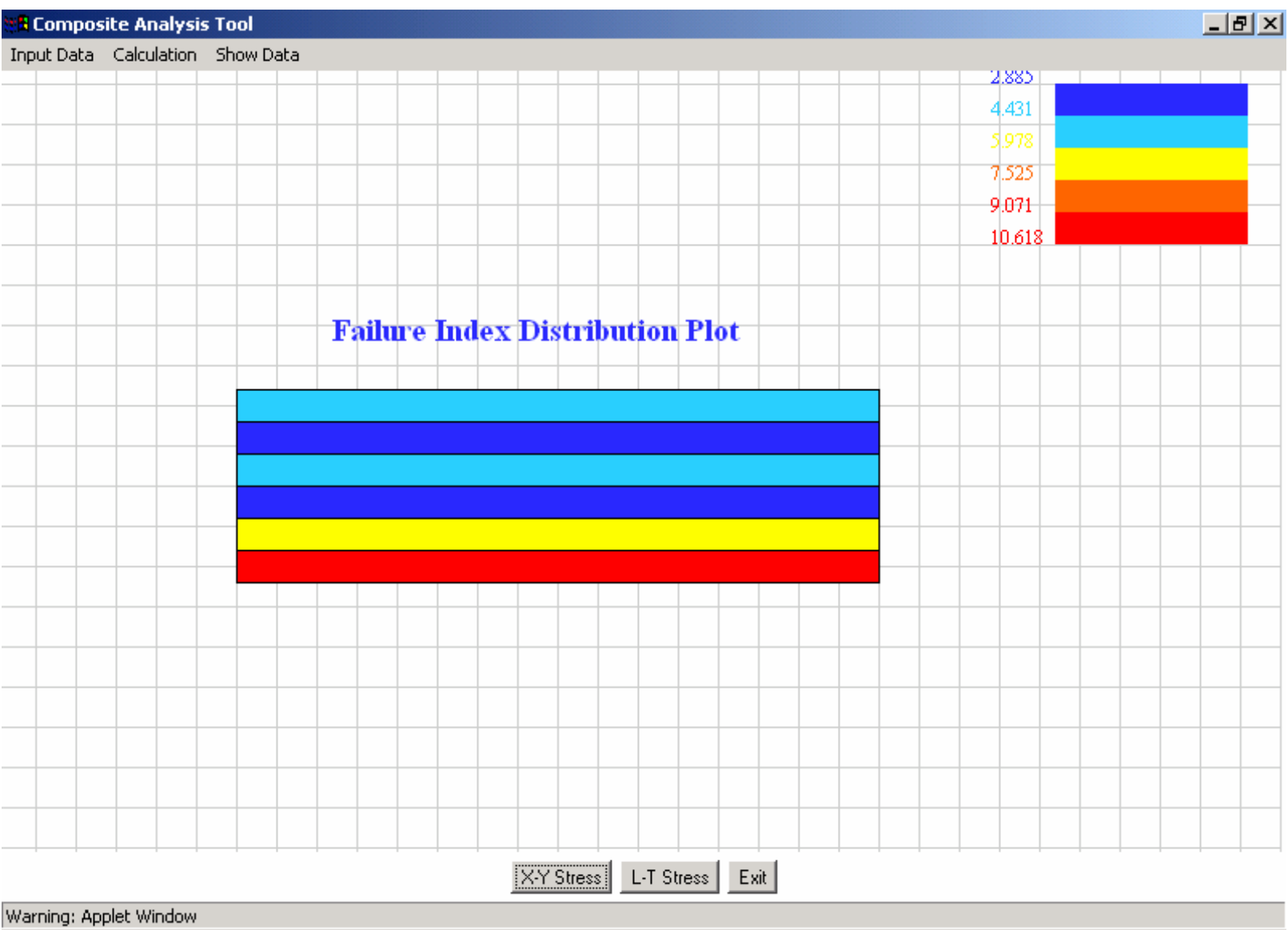

Figure 10: Failure Index Distribution Plot.

\section{Bibliography}

1. Agarwal, B. D. and L. J. Broutman. Analysis and Performance of Fiber Composites, John Wiley \& Sons, Inc., 1990.

2. Jones, M. R. Mechanics of Composite Materials, $2^{\text {nd }}$ Edition, Taylor \& Francis, Inc., Philadelphia, PA, 1999.

3. Estrada, H. (2004) CEEN 5316 - Engineering Mechanics of Fiber Composites, class notes, URL:

http://users.tamuk.edu/hector.estrada/ceen5316

4. ABAQUS, Hibbitt, Karlsson \& Sorensen, Inc. ABAQUS User's Manuals.

\section{Biographical Information}

DR. HECTOR ESTRADA is Associate Professor and Head of the Civil Engineering program at Texas A\&M University-Kingsville.

DR. FRANCISCO AGUINIGA is Assistant Professor of Civil Engineering at Texas A\&M University-Kingsville.

Proceedings of the 2005 American Society for Engineering Education Annual Conference \& Exposition Copyright (C) 2005, American Society for Engineering Education 